\title{
Use of Inhaled Tobramycin for the Treatment of Severe Nosocomial Pneumonia
}

\author{
Kuzovlev AN*, Moroz VV, Goloubev AM, Polovnikov SG, Stec VV and Varvarin VV
}

V.A Negovsky Scientific Research Institute of General Reanimatology RAMS, Moscow, Russia

\begin{abstract}
Objective: The objective of the study was to estimate the efficacy and safety of Inhaled Tobramycin (IT) as an adjunct to systemic antibiotics in the treatment of severe Nosocomial Pneumonia (NP).

Patients and methods: 25 mechanically ventilated patients (out of 165 screened) were enrolled in the current observational single-center study. They were randomized to receive either IT (300mg, BID; group 1, $\mathrm{n}=15$ ) as an adjunct to systemic antibiotics or for a correction of the regimen of systemic antibiotics (group 2, $n=10$ ). The primary outcome measure was resolution of NP and acute respiratory insufficiency. The CPIS, signs of Systemic Inflammatory Response Syndrome (SIRS) and oxygenation index were used as objective indicators of the clinical progress.

Results: The following signs of IT efficacy were detected in $87 \%$ of group 1 patients: a decrease of SIRS and CPIS scores within 2, $3 \pm 1,2$ days of IT therapy $(p<0,05)$; decrease of microbes titer to $10^{3}-10^{4} \mathrm{CFU} / \mathrm{ml}(p<0,05)$; increase of microbes sensitivity to systemic antibiotics in $40 \%$ of patients; positive X-ray dynamics in $60 \%$ of patients within 9,0 $\pm 2,5$ days of IT therapy. No serious side effects of IT were observed.
\end{abstract}

Conclusion: Administration of IT as an adjunct to systemic antibiotics is efficient and safe in $87 \%$ of patients with severe NP caused by multi resistant gram-negative bacteria.

Keywords: Nosocomial pneumonia; Sepsis; Tobramycin; Inhaled

\section{Introduction}

Nosocomial Pneumonia (NP) remains one of the significant problems of the intensive care units worldwide. Multiresistant gramnegative and gram-positive bacteria are prevalent agents of NP. Rational antibiotic therapy is the cornerstone of the treatment of NP. An early onset of antibiotic therapy improves the prognosis dramatically, but still the mortality and bacterial resistance are high. Pseudomonas aeruginosa, Acinetobacter spp., Burkholderia spp., Stenotrophomonas spp. present with a property to form biofilms which protect them against antibiotics and immune cells [1-4].

Intravenous antibiotics do not reach a bactericidial concentration in the tissue of lungs: intravenously administered antibiotics are primarily detected in the tracheobronchial tree of the lungs, but not in sputum. Increase of daily dose and combining different antibiotics often poses patients to side effects, superinfection and the selection of multiresistant bacteria [3,5-8]. Inhaled colistin, tobramycin, cephalosporins, amphotericin B, pentamidin have been used for prophylaxis and treatment of chronic and acute pseudomonal infections in patients with cystic fibrosis and bronchiectases for more than 50 years [9-14]. A 28 days course of the IT was proved to be effective in eradication of Pseudomonas aeruginosa in patients with cystic fibrosis [15].

Many research papers proved that inhaled antibiotics as adjuncts to systemic drugs decrease the degree of pulmonary inflammation facilitate weaning patients from ventilation, decrease microbial titer in Bronchoalveolar Lavage (BAL) fluid [16-19]. Lu Q et al. [20] showed a comparable clinical efficacy of systemic and inhaled cephalosporins and amikacin, but less frequent formation of multiresistant strains of Pseudomonas aeruginosa in the group of inhaled antibiotics [20]. Inhaled fluoroquinolones [21], liposomal aminoglycosides [22], aztreonam [23], combinations of inhaled antibiotics (phosphomycin/ tobramycin [24-25], colistin/tobramycin [26], ciprofloxacin/colistin [27]) were also clinically studied. Effect on biofilms is one of the significant mechanisms of the action of inhaled antimicrobials, which was proved by several experimental studies [26].

Inhaled antibiotics are not administered without systemic drugs because the degree of their adsorbtion is low (2-4\%) and insufficient for the treatment of infections associated with NP which is common in intensive care unit patients. The incidence of the side effects of inhaled antibiotics is low. One of the pitfalls of modern inhaled aminoglycosides is the small size of particles which speeds up their clearance from lungs $[9,26,28-32]$.

Only few clinical trials and case reports on IT in nosocomial pneumonia in critically ill patients were carried out $[16,32,33]$. The objective of the current study was to estimate the efficacy of IT as an adjunct to systemic antibiotics in the treatment of severe NP in critically ill patients.

\section{Materials and Methods}

Twenty five mechanically ventilated patients out of a cohort of 165 surgical Intensive Care Unit (ICU) patients were enrolled in the current observational single-center study within the period of 2009-2012 at the V.A. Negovsky scientific research institute of general reanimatology of the Russian academy of medical sciences (Moscow, Russia). The current study received the formal approval from the local Ethical Committee and written informed consents were obtained from all the enrolled subjects or their legal representatives. The research was conducted in accordance with the Declaration of Helsinki, national and institutional standards.

\section{Inclusion criteria}

Age 18-65 year old mechanically ventilated ICU patient; positive

*Corresponding author: Artem N Kuzovlev, V.A Negovsky Scientific Research Institute of General Reanimatology RAMS, build 2, 25 Petrovka str., Moscow 107031, Russia, Tel: 0079261887641; Email: artem_kuzovlev@mail.ru

Received August 20, 2012; Accepted September 25, 2012; Published September 27, 2012

Citation: Kuzovlev AN, Moroz VV, Goloubev AM, Polovnikov SG, Stec VV, et al. (2012) Use of Inhaled Tobramycin for the Treatment of Severe Nosocomial Pneumonia. J Pulmon Resp Med 2:130. doi:10.4172/2161-105X.1000130

Copyright: (c) 2012 Kuzovlev AN, et al. This is an open-access article distributed under the terms of the Creative Commons Attribution License, which permits unrestricted use, distribution, and reproduction in any medium, provided the original author and source are credited. 
NP criteria; failure of the current antibiotic regimen (absence of positive clinical dynamics of NP, progression of acute respiratory insufficiency and SIRS).

\section{Exclusion criteria}

APACHE II>26; acute kidney insufficiency, requiring hemodialysis; severe concomitant sub- or decompensated diseases of kidneys, liver, heart, vessels, diabetes mellitus; immune deficiency; hearing or vestibular disorders.

Twenty five patients were randomized in two groups: group 1 (interventional) and group 2 (control). The randomization was performed by the independent medical doctors using closed envelopes with a number of the investigation group inside. Group 1 received IT (group 1, $\mathrm{n}=15$ ) as an adjunct to systemic antibiotics; the basic antibiotic regimen remained unchanged. Group 2 experienced a correction of the regimen of systemic antibiotics (group $2, \mathrm{n}=10$ ) according to bacterial sensitivity to IV tigecycline ( $\mathrm{n}=3,30 \%)$; iv amikacin $1-1,5 \mathrm{~g}$ /day was added to therapy $(n=4,40 \%)$; daily dosage of iv meropenem was increased up to $6 \mathrm{~g}(\mathrm{n}=3,30 \%)$.

The primary outcome measure was resolution of NP and acute respiratory insufficiency. The CPIS, signs of SIRS and oxygenation index were used as objective indicators of the clinical progress. Nosocomial pneumonia was diagnosed according to the Russian national guidelines [34] and CPIS [35]. Pneumonias were bilateral and polysegmental in $100 \%$ of patients (confirmed by the X-rays (performed on enrollment, on days $5,7,14$ ) and computed tomography scans). Sepsis was diagnosed in $100 \%$ of patients on enrollment using the standard criteria [36-39].

All patients experienced a withdrawal of the biological samples for the microbiological essay (analyzer "VITEK Compact", Biomerieux, France) on enrollment, on days 5 and 7. BAL samples were taken during

\begin{tabular}{|c|c|c|c|}
\hline \multicolumn{2}{|c|}{$\begin{array}{c}\text { Group } 1(n=15) \\
\text { (inhaled tobramycin) }\end{array}$} & \multicolumn{2}{|c|}{$\begin{array}{c}\text { Group } 2(n=10) \\
\text { (intravenous antibiotics) }\end{array}$} \\
\hline Microbes & $\mathrm{N}$ of patients $(\%)$ & Microbes & $\mathrm{N}$ of patients $(\%)$ \\
\hline Pseudomonas aeruginosa & $12(80 \%)$ & $\begin{array}{l}\text { Pseudomonas } \\
\text { aeruginosa }\end{array}$ & $7(70 \%)$ \\
\hline $\begin{array}{l}\text { Acinetobacter baumanii/ } \\
\text { calcoaceticus }\end{array}$ & $9(60 \%)$ & $\begin{array}{l}\text { Acinetobacter } \\
\text { baumanii/ } \\
\text { calcoaceticus }\end{array}$ & $6(60 \%)$ \\
\hline Klebsilella pneumonia & $3(20 \%)$ & $\begin{array}{l}\text { Klebsilella } \\
\text { pneumonia }\end{array}$ & $3(30 \%)$ \\
\hline Proteus mirabilis & $3(20 \%)$ & Proteus mirabilis & $2(10 \%)$ \\
\hline $\begin{array}{l}\text { Staphylococcus aureus } \\
\text { MRSA }\end{array}$ & $1(7 \%)$ & \multirow[t]{2}{*}{$\begin{array}{l}\text { Staphylococcus } \\
\text { aureus MRSA }\end{array}$} & \multirow[t]{2}{*}{$1(10 \%)$} \\
\hline Enterococcus faecalis & $1(7 \%)$ & & \\
\hline
\end{tabular}

Table 1: Results of the microbiological studies of BAL. the bronchoscopy in the operation room or in the ICU. Transport media "MEUS S.r.l." (Piove di Sacco, Italy) was used. Associations of 2-4 multiresistant gram-negative microbes $10^{7}-10^{8} \mathrm{CFU} / \mathrm{ml}$ were detected in all patients. No reliable differences in the incidence of microbes were detected (Table 1).

At the moment of IT administration (group 1) or the correction of the antibiotic regimen (group 2) patients of both groups were treated with meropenem ( $1 \mathrm{~g}$ TID- $\mathrm{n}=20,80 \%$ ), imipenem/cilastatin (500 mg 4 times/day- $\mathrm{n}=3,12 \%)$, piperacillin/tazobactam $(4,5 \mathrm{~g}$ TID- $\mathrm{n}=2,8 \%) ; 3$ patients (12\%) were additionaly treated with lynezolid (600 mg BID) for Staphylococcus aureus infection. None of the patients received systemic aminoglycosides. All patients received standardized treatment.

Inhaled Tobramycin was administered in group 1 in case of inefficacy of the systemic antibiotics (no positive clinical dynamics and deterioration of the acute respiratory insufficiency and SIRS due to $\mathrm{NP}$ ), simultaneously with systemic antibiotics on day 6, $5 \pm 1$, 4 of the treatment of NP, $300 \mathrm{mg}$ BID. The daily dosage of IT was reduced to 300 $\mathrm{mg} /$ day in case of creatinine clearance less than $50 \mathrm{ml} / \mathrm{min}(\mathrm{n}=2,20 \%)$. Tobramycin was inhaled by "Aeroneb Pro" (Aeroneb, Ireland) nebulizer. The duration of IT therapy was $7,5 \pm 2,4$ days. The following criteria were used for the discontinuation of IT: positive clinical dynamics (decrease of SIRS and acute respiratory insufficiency signs). Systemic antibiotics were normally continued in group 1 for the treatment of the underlying infections.

Adverse events reporting, audiometry, and renal function were monitored to evaluate the tolerability and safety of the IT regimen. No patients were withdrawn from the study for adverse events.

Data were statistically analyzed by means of Statistica 7, 0 packs. Mean (M), standard deviation ( $\sigma$ ), Newman-Keuls test, Mann-Whitney test were calculated. $\mathrm{P}<0,05$ was considered statistically significant.

\section{Results and Discussion}

All patients enrolled in the study were males, aged $49 \pm 7,3$ yr. old No reliable differences in severity were detected between the groups prior the randomization: APACHE II on the day of enrollment was 18, 0 $\pm 3,2$ in group 1 and $17,7 \pm 3,5$ in group 2; Clinical Pulmonary Infection Score (CPIS) was $8,5 \pm 2,4$ in group 1 and $8,2 \pm 2,0$ in group 2 .

Nosocomial pneumonias were ventilator-associated in $100 \%$ of patients. NP developed in patients with severe intraabdominal infections (group $1 \mathrm{n}=8,54 \%$; group $2 \mathrm{n}=6,60 \%$ ), purulent mediastinitis (group $1 \mathrm{n}=4,27 \%$; group $2 \mathrm{n}=3,30 \%$ ), intracerebral abscesses (group 1 $\mathrm{n}=2,14 \%$; group $2 \mathrm{n}=1,10 \%$ ), tracheoesophageal fistulas (group $1 \mathrm{n}=1$, $5 \%$; group $2 \mathrm{n}=0$ ).

\begin{tabular}{|c|c|c|c|c|c|c|}
\hline & -1 day & Day 1 & Day 2 & Day 3 & Day 4 & Day 5 \\
\hline \multicolumn{7}{|c|}{ GROUP 1 (n=10) } \\
\hline Temperature, ${ }^{\circ} \mathrm{C}$ & $38,0 \pm 0,7$ & $38,1 \pm 0,5$ & $37,9 \pm 0,7$ & $37,6 \pm 0,5$ & $37,6 \pm 0,7$ & $37,4 \pm 0,8$ \\
\hline Leukocytosis, $10^{3} / \mathrm{mcl}$ & $14,9 \pm 9,7$ & $20,0 \pm 14,0$ & $13,6 \pm 8,7$ & $14,3 \pm 8,8$ & $11,8 \pm 7,8$ & $13,6 \pm 10,3$ \\
\hline Heart rate, $1 /$ мин & $101,2 \pm 12,1$ & $100,3 \pm 13,2$ & $98,5 \pm 10,3$ & $99,2 \pm 10,5$ & $92,6 \pm 13,2$ & $94,5 \pm 10,6$ \\
\hline Mean blood pressure, $\mathrm{mm} \mathrm{Hg}$ & $58,9 \pm 13,2$ & $61,5 \pm 11,0$ & $63,4 \pm 13,7$ & $59,3 \pm 8,0$ & $60,5 \pm 6,5$ & $68,2 \pm 11,1$ \\
\hline Oxygenation index, $\mathrm{mm} \mathrm{Hg}$ & $173,8 \pm 36,8$ & $195,0 \pm 60,1$ & $192,6 \pm 54,8$ & $206,1 \pm 44,6$ & $198,2 \pm 38,9$ & $200,8 \pm 38,5$ \\
\hline \multicolumn{7}{|c|}{ GROUP 2 (n=10) } \\
\hline Temperature, ${ }^{\circ} \mathrm{C}$ & $37,8 \pm 0,7$ & $38,1 \pm 0,6$ & $37,7 \pm 0,7$ & $37,5 \pm 0,6$ & $37,3 \pm 0,6$ & $37,5 \pm 0,7$ \\
\hline Leukocytosis, $10^{3} / \mathrm{mcl}$ & $11,2 \pm 3,9$ & $13,0 \pm 5,0$ & $14,3 \pm 5,4$ & $14,2 \pm 3,5$ & $16,5 \pm 8,1$ & $12,4 \pm 2,5$ \\
\hline Heart rate, $1 /$ мин & $105,7 \pm 11,1$ & $99,6 \pm 12,3$ & $97,5 \pm 11,0$ & $90,2 \pm 9,6$ & $94,2 \pm 10,2$ & $90,5 \pm 11,6$ \\
\hline Mean blood pressure, $\mathrm{mm} \mathrm{Hg}$ & $57,5 \pm 22,0$ & $63,6 \pm 6,5$ & $66,7 \pm 7,1$ & $63,7 \pm 9,6$ & $61,2 \pm 6,9$ & $63,1 \pm 5,1$ \\
\hline Oxygenation index, $\mathrm{mm} \mathrm{Hg}$ & $211 \pm 61,4$ & $219 \pm 65,8$ & $211,7 \pm 56,6$ & $216,6 \pm 60,7$ & $218,8 \pm 60,5$ & $216,3 \pm 65,8$ \\
\hline
\end{tabular}

Table 2: Dynamics of body temperature, leukocytosis, heart rate, mean blood pressure, oxygenation index in groups 1 and 2 within 5 days of investigation ( $\mathrm{M} \pm \sigma$ ). 


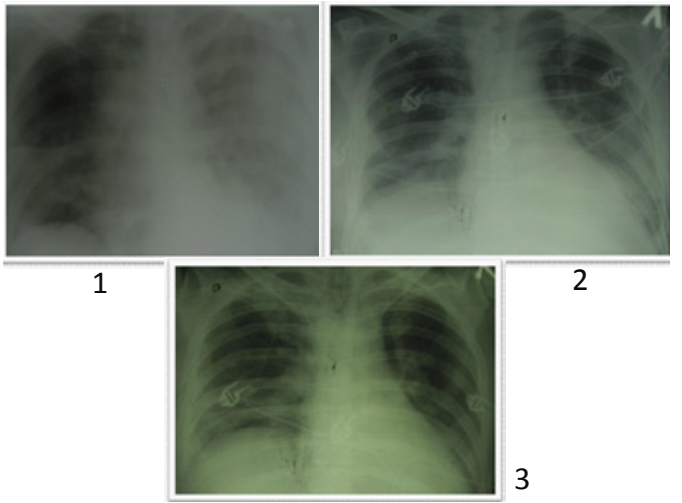

Figure 1: Positive X-ray dynamics in a patient treated with IT (1-before the treatment; $2-$ day 5 of treatment; $3-14$ days after the onset of treatment).

Table 2 deals with the dynamics of the key physiological parameters in groups 1 and 2. No statistically reliable differences (intergroup or between days) were obtained within 8 days of investigation, which can probably be explained by the small sample size and influences of the underlying diseases (peritonitis, mediastinitis, etc.)

Administration of IT in group 1 was clinically effective and decreased the signs of SIRS (decrease of body temperature, leukocytosis and amount of purulent discharge from the airways) and acute respiratory insufficiency (increase of the oxygenation index, decrease of the CPIS scores) within 2, $3 \pm 1,1$ days from the treatment start in 13 patients in group $1(87 \%)$. The decrease of SIRS signs in group 2 in comparison to group 1 was detected significantly later,6, $3 \pm 1,5$ days after the shift of antibiotics $(\mathrm{p}<0,05)$.

A significant decrease $(\mathrm{p}<0,05)$ of the titer of pathogenic microbes in BAL on days 5 and 7 in comparison of the titer on enrollment was detected: down to $10^{3-4} \mathrm{CFU} / \mathrm{ml}$ in group 1 ( $87 \%$ of patients) and in group 2 (50\% of patients). Microbes in BAL of 13 patients of group 1 were in vitro sensitive to tobramycin; 2 patients of group $1(13,4 \%)$ presented with in vitro resistance to tobramycin, but still the clinical efficacy of IT was shown in them - probably due to a high local concentration of the inhaled antibiotic [9,31]. An increase of the sensitivity of microbes to antibiotics they were resistant to, prior the IT therapy, was detected in group $1(40 \%)$, which is probably due to the action of IT on biofilms [26].

Positive X-ray and chest computed tomography dynamics was detected in 6 patients (40\%) of group 1 within 9, $0 \pm 2,5$ days (Figure 1 ); there were no such dynamics in group 2 . Three patients of group 1 were switched to the continuous positive airway pressure ventilation with pressure support on day $5,2 \pm 1,7$ of IT treatment.

In 2 patients of group 1 (13,4\%, underlying pathology intraabdominal infections) IT was ineffective and the antibiotic regimen was switched to IV tigecycline in standard doses, which finally provided us with a favourable outcome of NP. The failure of IT regimen was probably due to multi-resistant strains of Pseudomonas aeruginosa and Acinetobacter baumanii/calcoaceticus detected in these patients.

The mortality in group 1 was $27 \%(n=4)$, in group $2-30 \%(n=3)$. None of the deaths were associated with the progression of NP. Partial hearing loss and tinnitus were registered in 2 patients (14\%) of group 1 after the administration of IT. These symptoms resolved spontaneously 3 months after the discontinuation of IT. It is noteworthy that these patients had a very prolonged period of ICU stay (100-120 days) due to the severity of the underlying infections. Therefore, the influence of sepsis and other treatment modalities on the development of hearing loss and tinnitus cannot be excluded. There were no cases of bronchospasm or kidney damage registered, which corresponds well with the data of the other investigations [9, 29-32].

Future studies of our research group will focus on a mulitcenter trial in a larger population of ICU patients.

\section{Conclusions}

Administration of the inhaled tobramycin $300 \mathrm{mg}$ BID as an adjunct to systemic antibiotics is efficient and safe in $87 \%$ of patients in treatment of severe nosocomial pneumonia caused by multiresistant gram-negative bacteria.

\section{Acknowledgments}

May we acknowledge all the clinical and laboratory staff at the V.A. Negovsky scientific research institute of general reanimatology which strongly supported us during this investigation.

\section{Reference}

1. Karpun N, Moroz V, Klimova G Prophylaxis of nosocomial infections of respiratory tract. General Reanimatology 3: 100-104.

2. Torres A, Rello J (2010) Update in community-acquired and nosocomial pneumonia 2009. Am J Respir Crit Care Med 181: 782-787.

3. Høiby N (2011) Recent advances in the treatment of Pseudomonas aeruginosa infections in cystic fibrosis. BMC Med 9: 32.

4. Goloubev A, Smelaya T, Moroz VV, Popov AA, Tolbatov AA et al. Communityacquired and nosocomial pneumonia: clinical and morphological properties. General Reanimatology 4: 5-14

5. Luna CM, Vujacich P, Niederman MS, Vay C, Gherardi C, et al. (1997) Impact of BAL data on the therapy and outcome of ventilator-associated pneumonia. Chest 111: 676-685.

6. Kollef MH, Ward S (1998) The influence of mini-BAL cultures on patien outcomes: implications for the antibiotic management of ventilator-associated pneumonia. Chest 113: 412-420.

7. Iregui M, Ward S, Sherman G, Fraser VJ, Kollef MH (2002) Clinical importance of delays in the initiation of appropriate antibiotic treatment for ventilatorassociated pneumonia. Chest 122: 262-268

8. Moroz VV, Yu V Marchenkov, Lysenko DV, Karpun NA, Morozova OA Antibacterial therapy of nosocomial pneumonias caused by multiresistant strains in critically ill patients. General Reanimatology 3: 90-94

9. Dhand R (2007) The role of aerosolized antimicrobials in the treatment of ventilator-associated pneumonia. Respir Care 52: 866-884

10. Chermensky A, Gembitskaja TAdministration of inhaled tobramycin in patients with cystic fibrosis. Therapeutic archive 8: 76-79.

11. Kapranov $\mathrm{N}$ Clinical significance of the special aerosolized form of tobramycin in cystic fibrosis patients. Pulmonology 3: 20-26.

12. Kapranov N, Kashirskaja N, Nikonova V Out-of-patient administration of inhaled antibiotics in patients with cystic fibrosis. Clinical medicine 3: 35-40.

13. Amelina $E$, Chuchalin A Inhaled tobramycin in the treatment of Pseudomonas aeruginosa infection in cystic fibrosis patients. Pulmonology 5: 120-126.

14. Belousov Yu, Zyranov S, Sokolov A Efficacy and safety of an inhaled tobramycin for the treatment of Pseudomonas aeruginosa infection in cystic fibrosis patients. Pulmonology 2: 114-119.

15. Ratjen F, Munck A, Kho P, Angyalosi G; ELITE Study Group (2010) Treatmen of early Pseudomonas aeruginosa infection in patients with cystic fibrosis: the ELITE trial. Thorax 65: 286-291.

16. Avdeev S, Karchevskaja N, Chychalin AAdministration of inhaled tobramycin in nosocomial pneumonia. Clinical medicine 2: 80-88.

17. Drobnic ME, Suñé P, Montoro JB, Ferrer A, Orriols R (2005) Inhaled tobramycin in non-cystic fibrosis patients with bronchiectasis and chronic bronchial infection with Pseudomonas aeruginosa. Ann Pharmacother 39: 39-44.

18. Chuchalin A, Amelina E, Bianco F (2009) Tobramycin for inhalation in cystic 
Citation: Kuzovlev AN, Moroz VV, Goloubev AM, Polovnikov SG, Stec VV, et al. (2012) Use of Inhaled Tobramycin for the Treatment of Severe Nosocomial Pneumonia. J Pulmon Resp Med 2:130. doi:10.4172/2161-105X.1000130

fibrosis: Beyond respiratory improvements. Pulm Pharmacol Ther 22: 526 532.

19. Hudson R, Olson Blair B (2011) Inhaled antibiotics for gram-negative respiratory infections. Future Med Chem 3: 1663-1677.

20. Lu Q, Yang J, Liu Z, Gutierrez C, Aymard G, et al. (2011) Nebulized ceftazidime and amikacin in ventilator-associated pneumonia caused by Pseudomonas aeruginosa. Am J Respir Crit Care Med 184: 106-115.

21. Geller DE, Flume PA, Staab D, Fischer R, Loutit JS, et al. (2011) Levofloxacin inhalation solution (MP-376) in patients with cystic fibrosis with Pseudomonas aeruginosa. Am J Respir Crit Care Med 183: 1510-1516.

22. Okusanya OO, Bhavnani SM, Hammel J, Minic P, Dupont LJ, et al. (2009) Pharmacokinetic and pharmacodynamic evaluation of liposomal amikacin for inhalation in cystic fibrosis patients with chronic pseudomonal infection. Antimicrob Agents Chemother 53: 3847-3854.

23. Wainwright CE, Quittner AL, Geller DE, Nakamura C, Wooldridge JL, et al (2011) Aztreonam for inhalation solution (AZLI) in patients with cystic fibrosis, mild lung impairment, and P. aeruginosa. J Cyst Fibros 10: 234-242.

24. MacLeod DL, Barker LM, Sutherland JL, Moss SC, Gurgel JL, et al. (2009) Antibacterial activities of a fosfomycin/tobramycin combination: a novel inhaled antibiotic for bronchiectasis. J Antimicrob Chemother 64: 829-836.

25. Trapnell B, Rolfe M, McColley S Fosfomycin/tobramycin for inhalation (FTI): efficacy results of a phase 2 placebo-controlled trial in patients with cystic fibrosis and Pseudomonas aeruginosa. Pediatr Pulmonol 45: 302.

26. Herrmann G, Yang L, Wu H, Song Z, Wang H, et al. (2010) Colistin-tobramycin combinations are superior to monotherapy concerning the killing of biofilm Pseudomonas aeruginosa. J Infect Dis 202: 1585-1592.

27. Haagensen JA, Klausen M, Ernst RK, Miller SI, Folkesson A, et al. (2007) Differentiation and distribution of colistin- and sodium dodecyl sulfate-tolerant cells in Pseudomonas aeruginosa biofilms. J Bacteriol 189: 28-37.

28. Michalopoulos A, Fotakis D, Virtzili S, Vletsas C, Raftopoulou S, et al. (2008) Aerosolized colistin as adjunctive treatment of ventilator-associated pneumonia due to multidrug-resistant Gram-negative bacteria: a prospective study. Respir Med 102: 407-412
29. Michalopoulos A, Papadakis E (2010) Inhaled anti-infective agents: emphasis on colistin. Infection 38: 81-88.

30. Palmer LB, Smaldone GC, Chen JJ, Baram D, Duan T, et al. (2008) Aerosolized antibiotics and ventilator-associated tracheobronchitis in the intensive care unit. Crit Care Med 36: 2008-2013.

31. Ghannam DE, Rodriguez GH, Raad II, Safdar A (2009) Inhaled aminoglycosides in cancer patients with ventilator-associated Gram-negative bacteria pneumonia: safety and feasibility in the era of escalating drug resistance. Eur $J$ Clin Microbiol Infect Dis 28: 253-259.

32. Hallal A, Cohn SM, Namias N, Habib F, Baracco G, et al. (2007) Aerosolized tobramycin in the treatment of ventilator-associated pneumonia: a pilot study. Surg Infect (Larchmt) 8: 73-82.

33. Polovnikov S, Kuzovlev A, lljichev A Administration of inhaled tobramycin in severe nosocomial pneumonia (case report). Pulmonology 2: 109-112.

34. Chuchalin A Nosocomial pneumonia in adults. National guidelines. Moscow 2009

35. Pugin J, Auckenthaler R, Mili N Janssens JP, Lew PD, et al (1991) Diagnosis of ventilator-associated pneumonia by bacteriologic analysis of bronchoscopic and nonbronchoscopic "blind" bronchoalveolar lavage fluid. Am Rev Respir Dis 143: $1121-1129$

36. Moroz V, Goloubev A Diagnosis of the early stage of acute lung injury. Genera Reanimatology 4: 5-7.

37. Moroz V, Goloubev A Classification of acute respiratory distress syndrome. General Reanimatology 5-6: 7-9.

38. Kuzovlev AN, Moroz VV, Goloubev AM, Polovnikov SG (2010) Diagnosis of acute respiratory distress syndrome in nosocomial pneumonia. Semin Cardiothorac Vasc Anesth 14: 231-241.

39. Bone RC, Balk RA, Cerra FB, Dellinger RP, Fein AM, et al. (1992) Definitions for sepsis and organ failure and guidelines for the use of innovative therapies in sepsis. The ACCP/SCCM Consensus Conference Committee. American College of Chest Physicians/Society of Critical Care Medicine. Chest 101 1644-1655. 